\title{
State of art of seismic design and seismic hazard analysis for oil and gas pipeline system*
}

\author{
Aiwen Liu ${ }^{*}$ Kun Chen and Jian $\mathrm{Wu}$ \\ Institute of Geophysics, China Earthquake Administration, Beijing 100081, China
}

\begin{abstract}
The purpose of this paper is to adopt the uniform confidence method in both water pipeline design and oil-gas pipeline design. Based on the importance of pipeline and consequence of its failure, oil and gas pipeline can be classified into three pipe classes, with exceeding probabilities over 50 years of $2 \%, 5 \%$ and $10 \%$, respectively. Performance-based design requires more information about ground motion, which should be obtained by evaluating seismic safety for pipeline engineering site. Different from a city's water pipeline network, the long-distance oil and gas pipeline system is a spatially linearly distributed system. For the uniform confidence of seismic safety, a long-distance oil and pipeline formed with pump stations and different-class pipe segments should be considered as a whole system when analyzing seismic risk. Considering the uncertainty of earthquake magnitude, the design-basis fault displacements corresponding to the different pipeline classes are proposed to improve deterministic seismic hazard analysis (DSHA). A new empirical relationship between the maximum fault displacement and the surface-wave magnitude is obtained with the supplemented earthquake data in East Asia. The estimation of fault displacement for a refined oil pipeline in Wenchuan $M_{\mathrm{S}} 8.0$ earthquake is introduced as an example in this paper.
\end{abstract}

Key words: seismic hazard assessment; oil and gas pipeline; fault displacement

CLC number: P315.9 Document code: A

\section{Introduction}

Oil and gas pipelines in China are generally designed and constructed as buried pipes for economic, safe and environmental reasons. The large gas fields in China are located in western part, whereas most of gas users are concentrated in eastern China, for example, the West-East Gas Pipeline from Urumqi to Shanghai was constructed in 2002 and the length of pipeline is up to 4 $000 \mathrm{~km}$. These oil and gas pipelines are important lifeline facilities, spreading over a large area. Many oil or gas pipelines have to run through areas with high seismic activity and are therefore exposed to considerable seismic risk. Figure 1 shows the location of main oil and gas pipelines operated by China National Petroleum Corporation (CNPC) and the distribution of earthquakes with magnitude larger than 6 in China.

A new seismic code for oil and gas transmission pipelines in China has been issued on July 1, 2009

\footnotetext{
* Received 18 August 2009; accepted in revised form 21 April 2010; published 10 June 2010.

^ Corresponding author. e-mail: law73@163.com

(C) The Seismological Society of China and Springer-Verlag Berlin Heidelberg 2010
}

(CNPC, 2009). All oil and gas pipeline constructions in Chinese mainland should be designed to comply with the requirements of the new seismic code. The code document has been prepared in accordance with generally recognized engineering principles and practices in China, and many international codes, standards and guidelines have also been referenced. Besides functional design, pipeline safety should be checked for all possible ground motions, which may be encountered, and seismic loads simultaneously with the operating loads (pressure, temperature, initial bending, etc). Pipelines running through active seismic zones should be designed in such a way that they remain function even after being suffered from high intensity earthquake shaking. The performance-based seismic design of oil and gas pipelines include: (1) serviceability requirements of that the pipeline should maintain its supply capability as much as possible, even with considerable local damage due to high intensity earthquakes; (2) safety requirements of that the population and environmental damage originated from pipeline rupture should be considered (Liu and Feng, 2007).

To identify earthquake hazards, evaluation of seismic safety for pipeline engineering sites is carried out to 
provide how the hazard affects pipelines and to define parameters needed to quantify the earthquake hazards for pipeline design. Because the pipeline performance-based design requires more information on ground motion, it leads to a higher requirement to the evaluation of seismic safety for pipeline engineering sites. Recommended by American Lifelines Alliance (shorted as ALA, 2005), the transient ground motion is used to describe the shaking hazard by seismic waves and the amplifications due to surface and near-surface ground conditions and topography, including peak ground acceleration (PGA), peak ground velocity (PGV), response spectrum $\left(S_{\mathrm{a}}\right)$ and ground motion history, $a(t)$. Permanent ground displacement (PGD) describes the ground failures resulting from surface fault rupture, slope movements and landslides, liquefaction- induced lateral spreading and flow failure, and differential settlement. In general, an oil and gas pipeline system includes pump stations, buried pipe, the above-mentioned ground pipe and pipe bridges when crossing rivers. Table 1 summarizes the transient and permanent ground movement hazards to be considered during the oil and gas pipeline design following the recommendation of ALA.

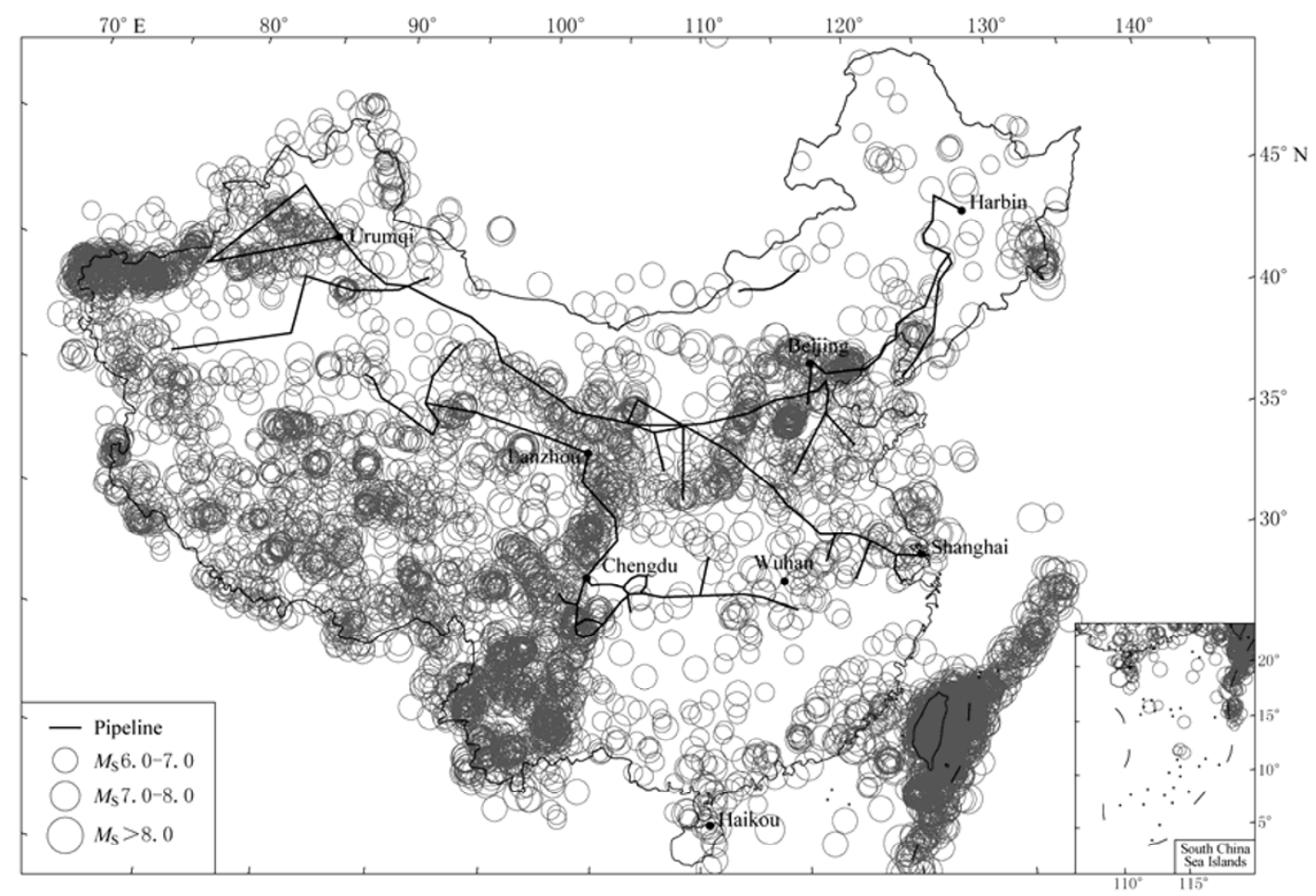

Figure 1 Location of the main oil and gas pipelines operated by CNPC and distribution of earthquakes with magnitude larger than 6 in China.

Table 1 Seismic hazards for oil and gas pipelines

\begin{tabular}{|c|c|c|c|}
\hline Hazard & Oil and gas pipeline system & Earthquake parameters & Source \\
\hline Ground shaking & $\begin{array}{l}\text { Buried pipe } \\
\text { Pipe bridge, above-ground pipe, pump stations }\end{array}$ & $\begin{array}{l}\text { PGA, PGV, } T_{\mathrm{g}}, v_{\mathrm{S}} \\
\text { PGA, PGV, } T_{\mathrm{g}}, S_{\mathrm{a}}, a(t)\end{array}$ & $\begin{array}{l}\text { Probabilistic seismic hazard } \\
\text { analysis (PSHA) }\end{array}$ \\
\hline Faulting & Buried pipe, above-ground pipe & $\begin{array}{l}\text { Expected amount of fault displacement, } \\
\text { crossing angle }\end{array}$ & $\begin{array}{l}\text { Deterministic seismic hazard } \\
\text { analysis DSHA }\end{array}$ \\
\hline Liquefaction & Buried pipe, above-ground pipe, pipe bridge & $\begin{array}{l}\text { PGA, magnitude, length of pipeline } \\
\text { exposed to PGD }\end{array}$ & Disaggregated PSHA \\
\hline Differential settlement & Buried pipe, above-ground pipe, pipe bridge & $\begin{array}{l}\text { PGA, magnitude, length of pipeline } \\
\text { exposed to PGD }\end{array}$ & Disaggregated PSHA \\
\hline
\end{tabular}

Note: $T_{\mathrm{g}}$ is site natural period, $v_{\mathrm{S}}$ is shear velocity of soil, $S_{\mathrm{a}}$ is response spectrum, and $a(t)$ is ground motion history.

A uniform confidence methodology for the design of water pipeline systems has been proposed by Davis
(2005). This method was adopted by the American Lifelines Alliance (2005). The uniform confidence hazard 
evaluation provides a method to assess earthquake risk so that all pipes in a water system are designed to be consistent with their intended function, with a uniform confidence that design forces are greater than or equal to the actual forces, which a pipe may experience during an earthquake. The water pipe function is defined by its importance in post-earthquake response and recovery. A more important function of pipe service (for example, a water pipe for fire fighting) needs to have stricter seismic criteria to ensure that the design value is greater than the actual seismic force.

Different from a city's water pipeline network, the scale of oil and gas pipelines can vary from kilometers to thousands of kilometers; it is a spatially linearly distributed system. The main purpose of this paper is to extend the uniform confidence methodology used in water pipeline design to oil or gas pipeline design. Following the new seismic code for oil and gas transmission pipelines in China, the uniform confidence method adopted in the seismic design of oil and gas pipelines in China is introduced.

\section{Design level of seismic safety}

The design level of seismic safety for an oil and gas pipeline in China depends on the importance of the pipeline and the consequences of its failure. Oil and gas pipelines have been classified into three groups as follows.

Class I: Oil and gas pipelines that are vital energy supply facilities are required to remain functionality during and following the design earthquake. Failure or damage to pipelines would cause extensive loss of life or a major impact on the environment, for example, a pipeline crossing a main river in eastern China.

Class II: Oil and gas pipelines that pose a substantial hazard to human life and property in the event of failure but their service can be interrupted for a short period until minor repairs are made.

Class III: Other oil and gas pipelines. For a very long pipeline, the whole pipeline can also be divided into three classes of pipe segments with the same criterion.

The seismic risk level accepted for design depends on the class of pipe, adopting the probability of exceedance in 50 years, as shown in Table 2.

Table 2 Design levels of seismic risk

\begin{tabular}{ccc}
\hline Pipe class & Probability of exceeding in 50 years & Return period/a \\
\hline I & $2 \%$ & 2475 \\
II & $5 \%$ & 975 \\
III & $10 \%$ & 475 \\
\hline
\end{tabular}

\section{Pipeline seismic hazard analysis for transient ground movements}

Transient ground movements refer to the transient soil deformations (i.e., strain and curvature in the ground) due to seismic wave propagation and affect the pipeline over a large area with widely dispersed damage. Ground shaking does not have a serious effect on buried oil and gas pipelines in good condition except points at the transition between very stiff and very soft soils, penetration into valve boxes, locations at or near pump stations, T-connections, pipe fittings and valves. However, pipelines weakened by corrosion are more vulnerable to damage during ground shaking. The ground shaking is often characterized by PGV, rather than by PGA.

The design basis for earthquake ground motion (in terms of PGA and PGV) should be estimated based on site-specific pipeline seismic hazard analysis (PSHA). PSHA itself has also been modified for the determination of seismicity model, regional attenuation law and the analysis of uncertainties. In China, the following specific standards adequately deal with the seismic evaluation and design for oil and gas pipelines, that is, a Seismic Ground Motion Zonation Map of China (China Earthquake Administration, 2001) and the Evaluation of Seismic Safety for Engineering Sites (China Earthquake Administration, 2005).

Compared with a city's water pipeline network, an oil and gas pipeline system is a spatially linearly distributed system, which is composed of a series of pipe segments and pump stations linearly distributed in space. When a part of the oil and gas pipeline system is destroyed by an earthquake, the pipe's function also fails (Gao, 1993). Therefore the pipeline system should be considered as a whole. In the PSHA models currently used for the seismic evaluation are all for a single site. When we consider the total seismic risk for an oil and gas pipeline system, PSHA models for sites alone are insufficient. There are two methods for considering the overall seismic risk of oil and gas systems: the Monte Carlo simulation method and simplified methods (Guo et al, 2009).

Considering an oil and gas pipeline with $n$ pump stations, the ground motion has little effect on buried pipes and the main serious effects are those on pump stations. The total seismic risk for an oil and gas system due to ground motion, $P$, is

$$
P=1-\prod_{i=1}^{n}\left(1-P_{i}\right),
$$


where $P_{i}$ is the exceedance probability of pump station, $i$ When the exceedance probability of each pump station has the same value, equation (1) can be simplified to

$$
P=1-\left(1-P_{i}\right)^{n} \text {. }
$$

In fact, ground shaking does not have a serious effect on buried pipelines. As already stated, the performance of refined oil pipeline in Wenchuan earthquake, the seismic design of a pipeline system should pay attention to both the pipe segments and pump stations for the uniform confidence of seismic safety.

\section{Fault displacement hazard analyses}

Catastrophic failures of buried pipeline did occur in many earthquakes, particularly under the large fault displacement. Based on the investigation of pipeline damage in the 1995 Kobe earthquake, the 1999 Jiji earthquake and the 1999 Kocaeli earthquake, PGD poses the greatest damage to a buried pipeline. Therefore, the assessment of permanent ground displacement is very important for the design of oil and gas pipelines crossing active faults.

DSHA has been proposed to estimate the PGD induced by liquefaction and landslide. The PSHA for fault displacement is developed within the framework of probabilistic seismic hazard analysis (Youngs et al, 2003; Todorovska et al, 2007). The earthquake occurrences are also modeled as Poissonian sequences. In addition to earthquake occurrence rates, PSHA for fault displacement also requires the probability distribution function of displacement along the fault line and probabilities that a rupture will affect the site. The distribution of displacement along the fault line is strongly dependent on the source mechanism of the earthquake and the rupture of the site for pipelines crossing faults needs further research. Preliminary research results show that the hazard is light even for very low levels of displacement, in contrast to the ground shaking hazard, because only one fault contributes to the hazard and not every event on that fault necessarily affects the site.

The PGD induced by fault movement is still primarily determined by DSHA in China. Fault displacement can be estimated using historical evidence, paleoseismic evidence and/or slip rate calculations. Usually the maximum fault displacement $\left(D_{\max }\right)$ is estimated by an empirical relationship with earthquake magnitude $(M)$ as follows:

$$
\log _{10} D_{\max }=A \cdot M-B
$$

where $A$ and $B$ are the regression coefficients (Wells and Coppersmith, 1994).

The maximum fault displacement depends on the magnitude of future earthquake on this fault. To consider the uncertainty in the magnitude of the earthquake, as well as the uncertainty in the amount of displacement, given the occurrence of a particular magnitude earthquake, a more refined approach for DSHA is to define the design-basis fault displacements corresponding to three pipeline classes. In another words, the design-basis fault displacement of pipe class $I$ is larger than that of pipe class III, as shown in Table 3.

Table 3 Design-basis fault displacement for oil and gas pipelines

\begin{tabular}{ccl}
\hline Pipe class & $\begin{array}{c}\text { Probability of exceedance } \\
\text { in 50 years }\end{array}$ & $\begin{array}{l}\text { Design-basis fault } \\
\text { displacement }\end{array}$ \\
\hline I & $2 \%$ & $\log _{10} D_{\max }=A \cdot M-B+\sigma$ \\
II & $5 \%$ & $\log _{10} D_{\max }=A \cdot M-B+\sigma / 2$ \\
III & $10 \%$ & $\log _{10} D_{\max }=A \cdot M-B$ \\
\hline
\end{tabular}

Note: $\sigma$ is standard deviation.

The standard deviation becomes very important when deciding upon the design-basis fault displacement. Based on the research of Wells and Coppersmith (1994), fault displacement data of 60 earthquakes in East Asia, as well as the maximum fault displacement of the $M_{\mathrm{S}} 8.0$ Wenchuan earthquake, were supplemented. A new empirical relationship between $D_{\max }$ and the surface-wave magnitude $\left(M_{\mathrm{S}}\right)$ was obtained using 186 earthquake data values. As shown in Table 4 and Figure 2, the result of the regression is improved and the standard deviation $\sigma$ is 0.38 .

As an example, before the Wenchuan earthquake, the maximum magnitude of the potential earthquake on Longmenshan fault zone was assumed as 7.5 based on the largest history earthquake in this area, Diexi $M_{\mathrm{S}} 7.5$ earthquake in 1933 (China Earthquake Administration, 2001, 2005). For the seismic design of the Lanzhou-Chengdu-Chongqing refined oil pipeline with this proposed $M_{\mathrm{S}} 7.5$ earthquake, the maximum fault displacement would be only $3.1 \mathrm{~m}$ without considering the uncertainty of magnitude, but if the data in Table 3 are adopted, additionally this refined oil pipeline is very important and runs through the high density population area, the class of this pipeline is considered as Class I, then the design fault displacement will be $7.4 \mathrm{~m}$, almost equal to the observed total fault displacement of $7.9 \mathrm{~m}$ in Wenchuan earthquake (Xu et al, 2008). 
Table 4 Regressions of $D_{\max }$ and earthquake magnitude

\begin{tabular}{llccccc}
\hline Authors & Equation & $r$ & $\sigma$ & Data & Magnitude range & Slip type \\
\hline This paper & $\log _{10} D_{\max }=0.669 M_{\mathrm{S}}-4.528$ & 0.82 & 0.38 & 186 & $4.6-8.7$ & Strike-slip, normal, and reverse faulting \\
Wells and Coppersmith (1994) & $\log _{10} D_{\max }=0.82 M-5.46$ & 0.78 & 0.42 & 80 & $5.2-8.1$ & Strike-slip, normal, and reverse faulting \\
\hline
\end{tabular}

Note: $D_{\max }$ is maximum displacement in unit of $\mathrm{m}, r$ is correlation coefficient, $M$ is moment magnitude.

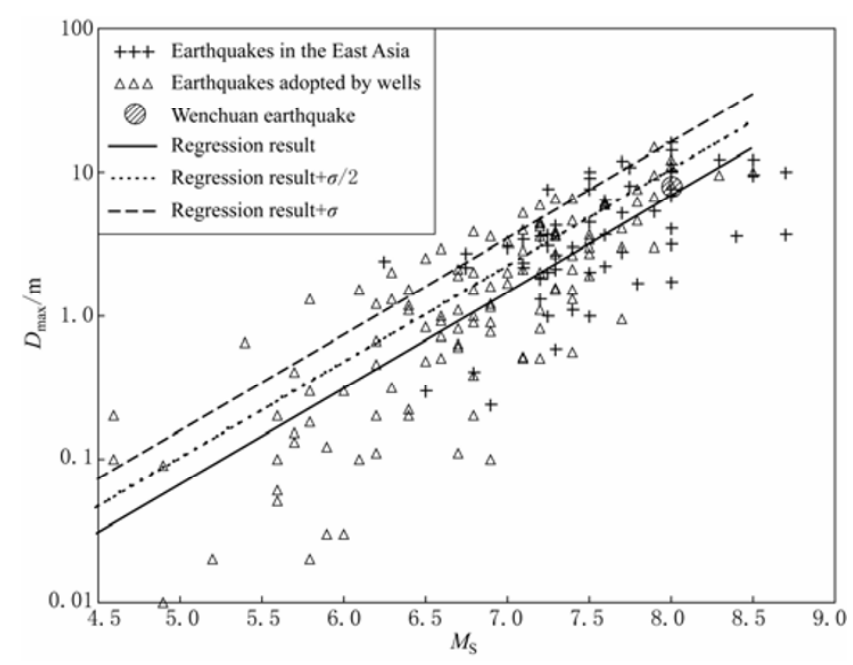

Figure 2 Maximum displacement $\left(D_{\max }\right)$ versus surface-wave magnitude $\left(M_{\mathrm{S}}\right)$.

\section{Discussion and conclusions}

For the uniform confidence of seismic safety, a long-distance oil and gas pipeline formed with numbers of pump stations and pipe segments should be considered as a whole system when analyzing seismic hazards. According to the new code in China, oil and gas pipelines have been classified into three classes based on the importance of the pipeline and the consequence of its failure, with probabilities of exceedance in 50 years of $2 \%, 5 \%$ and $10 \%$, respectively. Although buried oil and gas pipelines usually stand strong ground shaking in many disastrous earthquakes, the seismic designs of pump stations and other necessary facility are very important for the uniform confidence of the seismic safety. Because the uncertainty of future earthquake magnitude always exits, the design fault displacement for an important oil and pipeline is better to consider the standard deviation in the result of DSHA.

Acknowledgements This research was jointly supported by the National Scientific and Technological support project MST (2006BAC13B02-0106) and special research funds from the Public Institute of China, Institute of Geophysics (IGP), China Earthquake Administration (CEA) (DQJB06A01). The contribution No. is 10FE3004, IGP, CEA.

\section{References}

American Lifelines Alliance (2005). Design Guidelines for Seismic Resistant Water Pipeline Installations. FEMA and National Institute of Building Sciences. 2009-10-01, www.americanlifelinesalliance.org.

China Earthquake Administration (2001). Seismic Ground Motion Parameter Zonation Map of China. China Standard Press, Beijing, 1-6 (in Chinese).

China Earthquake Administration (2005). Evaluation of Seismic Safety for Engineering Sites. China Standard Press, 4-14 (in Chinese).

Davis C A (2005). Uniform confidence hazard approach for the seismic design of pipelines. The 4th Japan-US Workshop on Seismic Measures for Water Supply. JWWA and AWWARF, Kobe, Japan, 149-157.

Gao M T (1993). Seismic hazard analysis for a spatial linearly distributed system. Acta Seismologica Sinica 6(3): 713-719.

Guo X, Pan H and Gao M T (2009). Seismic hazard analysis of cascade hydropower stations system by the Monte Carlo method. Earthquake Research in China 25(1): 94-99 (in Chinese with English abstract).

China National Petroleum Corporation (2009). Seismic Technical Code for Oil and Gas Transmission Pipeline Engineering. China Standard Press, Beijing, 9-12 (in Chinese).

Liu A W and Feng Q M (2007). The new seismic code for oil and gas transmission pipelines of China. In: The Fifth China-Japan-US Trilateral Symposium on Lifeline Earthquake Engineering. Nov. 26 to 30, 2007, Haikou, China.

Todorovska M I, Trifunac M D and Lee V W (2007). Shaking hazard compatible methodology for probabilistic assessment of permanent ground displacement across earthquake faults. Soil Dynamics and Earthquake Engineering 27(6): 586-597.

Wells D L and Coppersmith K J (1994). New empirical relationships among magnitude, rupture length, rupture width, rupture area, and surface displacement. Bull Seism Soc Amer 84: 974-1 002.

Xu X W, Wen X Z, Ye J Q, Ma B Q, Chen J, Zhou R J, He H L, Tian Q J, He Y L, Wang Z C, Sun Z M, Feng X J, Yu G H, Chen L C, Chen G H, Yu S E, Ran Y K, Li X G, Li C X and An Y F (2008). The $M_{\mathrm{S}} 8.0$ Wenchuan earthquake surface rupture and its seismogenic structure. Seismology and Geology 30(3): 597-627 (in Chinese with English abstract).

Youngs R R, Arabasz W J, Anderson R E, Ramelli A R, Ake J P, Slemmons D B, McCalpin J P, Doser D I, Fridrich C J, Swan F H, Rogers A M, Yount J C, Anderson L W, Smith K D, Bruhn R L, Knuepfer P L K, Smith R B, DePolo C M, O'Leary D W, Coppersmith K J, Pezzopane S K, Schwartz D P, Whitney J W, Olig S S and Toro G R (2003). A methodology for probabilistic fault displacement hazard analysis (PFDHA). Earthquake Spectra 19(1): 191-219. 